doi: $10.15407 /$ ujpe62.05.0365

I.Z. INDUTNYI, YU.V. USHENIN, V.I. MYN'KO, P.E. SHEPELIAVYI, M.V. LUKANIUK, A.A. KORCHOVYI, R.V. KHRYSTOSENKO

V.E. Lashkaryov Institute of Semiconductor Physics, Nat. Acad. of Sci. of Ukraine (41, Nauky Ave., Kyiv 03028, Ukraine; e-mail: indutnyy@isp.kiev.ua)

PACS 73.20.Mf, 87.85.fk, 81.16. Nd

\title{
NANOSTRUCTURED Au CHIPS \\ WITH ENHANCED SENSITIVITY FOR SENSORS BASED ON SURFACE PLASMON RESONANCE
}

\begin{abstract}
The enhancement of the sensitivity of a surface-plasmon-resonance refractometer by forming a periodic relief in the form of a grating with a submicron period on the surface of an Au chip has been studied. Periodic reliefs with the spatial frequency $\nu=(3370 \pm 5)$ line $/ \mathrm{mm}$ and various depths were formed on the Au film surface using interference lithography and vacuum chalcogenide photoresists. The degree of refractometer sensitivity enhancement and the variation interval of the environment refractive index, $\Delta n$, in which this enhancement is observed, are found to depend on the grating relief depth. The interval $\Delta n$ decreases with the growth of the relief depth, whereas the sensitivity increases from $110 \mathrm{deg} / R I U$ for a standard chip to 154 and $363 \mathrm{deg} / \mathrm{RIU}$ for structured chips with relief depths of $11.7 \pm 2$ and $18.5 \pm$ $\pm 2 \mathrm{~nm}$, respectively.

Ke ywords: surface plasmon resonance, biosensors, interference lithography, vacuum chalcogenide photoresists.
\end{abstract}

\section{Introduction}

A possibility for the surface plasmon resonance (SPR) phenomenon to be applied in sensorics was demonstrated in 1982 [1]. Since then, a rapid progress has been observed in the researches and developments of sensors on the basis of SPR owing to their high sensitivity and a capability to quickly detect in situ processes running in a medium near the metal film surface. SPR-based sensors are applied to measure various physical and chemical quantities such as electric field [2], pressure [3], gas concentration [1], and so forth. However, they found the most wide scope of application as biosensors [1], to study bimolecular interactions [4], for medical diagnostics [5], and to analyze foodstuff and environment $[6,7]$.

(C) I.Z. INDUTNYI, YU.V. USHENIN, V.I. MYN'KO, P.E. SHEPELIAVYI, M.V. LUKANIUK,

A.A. KORCHOVYI, R.V. KHRYSTOSENKO, 2017
In the majority of serial SPR devices, surface plasmon waves are excited with the use of the total internal reflection in a prism (the Kretschmann method) [8]. Nevertheless, biosensors of this type have some shortcomings. In particular, their sensitivity is not sufficient for a reliable detection of the interaction between proteins and ligands with small dimensions [9]. Therefore, the enhancement of the sensitivity of SPR-based sensors is a challenging task for researchers. In the last years, a number of modifications were proposed for thin-film structures on the basis of gold layers, which are used as chips in SPR sensors. In particular, these are the deposition of gold nanoparticles or gold nanowires on the surface of $\mathrm{Au}$ films [10,11], the deposition of a thin dielectric layer containing gold nanoparticles on the surface of an $\mathrm{Au}$ chip [12], and others.

In theoretical researches [13], it was shown that the formation of a periodic grating on the surface of 
a metal layer in the chip of an SPR biosensor operating in the Kretschmann configuration can make the device several times more sensitive in comparison with standard chips with planar metal surfaces. A surface plasmon is excited in the direction perpendicular to grating grooves, and it can be reflected backward. If the grating period is selected so that the conditions of Bragg reflection are satisfied, the propagation of surface plasmons is forbidden (an energy gap is formed). By choosing the working zone of a sensor in a vicinity of the forbidden gap (by varying the grating period and the relief depth), it is possible to obtain an enhanced sensitivity of the plasmon maximum position to the variation of the refractive index in the medium near the chip surface in comparison with the case of planar Au layers.

Nanostructures with a periodic relief are formed with the use of modern lithographic technologies: electron- or ionic-beam lithography $[14,15]$, nanosphere lithography [16], nanoimprinting [17], optical lithography in the far ultra-violet region [18], and other rather expensive technological processes. As a result, the cost of such structures is too high, which makes their wide application doubtful. At the same time, interference lithography (IL), which can be used for the formation of ordered metal nanostructures $[19,20]$, is cheaper and more technological. A considerable advantage of IL is a possibility to quickly form a perfect periodic structure on a large area with the use of a single exposure to the interference field of laser radiation. The area extension is confined by only the intensity and the coherence length of a laser.

In the previous researches [21, 22], the authors showed that IL together with the application of a high-resolution vacuum photoresist on the basis of chalcogenide glasses comprises a promising technology for the formation of one- and two-dimensional submicron periodic structures on the surfaces of metal films, semiconductors, and insulators. In our previous work [23], we experimentally demonstrated for the first time that the sensitivity of an SPR sensor operating in the Kretschmann configuration can be increased by forming a periodic relief on the Au chip surface. In this work, a more detailed study of plasmon excitation conditions in films with a relief surface in the form of high-frequency gratings, as well as the change of their optical response with the relief depth, is carried out.

\section{Experiment}

Experimental specimens were prepared by the thermal evaporation in a vacuum of $2 \times 10^{-3} \mathrm{~Pa}$ and the subsequent deposition of an adhesive $\mathrm{Cr}$ layer $3 \mathrm{~nm}$ in thickness, a metal $(\mathrm{Au})$ layer $40-50 \mathrm{~nm}$ in thickness, and a chalcogenide glass layer $\left(\mathrm{As}_{40} \mathrm{~S}_{60}\right.$ or $\left.\mathrm{As}_{40} \mathrm{~S}_{40} \mathrm{Se}_{20}\right)$ 80-100 $\mathrm{nm}$ in thickness onto substrates. For this purpose, polished $20 \times 20 \times 1-\mathrm{mm}^{3}$ plates of glass F1 (the refractive index $n=1.615$ ) were used. During the film deposition, the thickness was monitored with the help of a quartz thickness gage KIT-1. After the deposition, the total thickness of the thin-film structure was measured with the use of a microinterferometer MII-4.

Interference structures were recorded on chalcogenide glass films by means of an interference pattern produced by the radiation of a helium-cadmium laser (the wavelength $\lambda=441.6 \mathrm{~nm}$ ) with the given spatial frequency. The exposure magnitude at the grating recording amounted to $0.2-0.5 \mathrm{~J} / \mathrm{cm}^{2}$. After the exposition, the specimens were treated in a selective etchant on the basis of amines in order to form a lithographic mask, through which the metal film was etched. The photoresist etching was monitored in situ by registering non-photoactive long-wave light that was diffracted from the relief structure formed in the photoresist layer. After the photoresist remnants had been removed by the alkali solution, the specimens were washed out and dried to obtain a formed periodic metal structure.

The periodic structure was formed only on one half of the chip, whereas the other half remained covered with a non-structured gold film. Such specimens were fabricated for comparative researches on a two-channel device. In this work, we used a two-channel SPR refractometer PLAZMON-71 developed at V.E. Lashkaryov Institute of Semiconductor Physics of the National Academy of Sciences of Ukraine. The experiment was carried out in the Kretschmann configuration. A semiconductor laser with a wavelength of $850 \mathrm{~nm}$ was used as a radiation source.

For the determination of the shape of profile elements in the relief of a periodic structure and their dimensions, a Dimension 3000 Scanning Probe Microscope (Digital Instruments Inc., Tonawanda, NY, USA) was used. The spatial grating frequency was determined with the help of an optical stand on the 
basis of a goniometer G5M with a measurement accuracy of \pm 5 line $/ \mathrm{mm}$.

\section{Results and Their Discussion}

The SPR refractometer PLAZMON-71 allows the angular dependences of the internal reflection intensity, $R(\theta)$, for a gold film to be measured and the position of the $R(\theta)$ minimum to be determined. The latter corresponds to the excitation of surface plasmons at the $\mathrm{Au}$ film-environment interface. The position of the $R(\theta)$ minimum is very sensitive to the variation of the refractive index $n$ of the medium near the $\mathrm{Au}$ film surface. This fact makes it possible to register processes resulting in even very small changes of $n$ in this region. In order to determine the sensor sensitivity of the structures, i.e. the influence of the environment refractive index on the resonance minimum shift, we used solutions of glycerol (the refractive in$\operatorname{dex} n=1.474$ at $\left.20^{\circ} \mathrm{C}\right)$ in water $\left(n=1.333\right.$ at $\left.20^{\circ} \mathrm{C}\right)$ in this work. The solution concentration was varied within the interval of 34-64 wt.\% of glycerol, and the solution refractive index changed from 1.37 to 1.42 at that. The solution was introduced into a two-channel flow-through cell. The latter was arranged above the examined specimen in such a way that a contact between the liquid and the structure was provided. One of the channels corresponded to the reference gold film, and the other to the nanostructured film (with a surface relief in the form of a grating).

The spatial frequency of the grating was chosen to be close to that corresponding to the Bragg reflection condition. A theoretical simulation in work [13] was made for gratings with a sinusoidal profile and small relief depths. In this case, one can approximately evaluate the Bragg period of the lattice, $\Lambda_{\mathrm{B}}$, with the help of the simple formula

$\Lambda_{\mathrm{B}}=0.5 \lambda_{0}\left[\left(\varepsilon_{m r}+\varepsilon_{D}\right) / \varepsilon_{m r} \varepsilon_{D}\right]^{1 / 2}$,

where $\lambda_{0}$ is the light wavelength in vacuum, $\varepsilon_{D}$ the dielectric constant of the medium, and $\varepsilon_{m r}$ the real part of the metal dielectric constant. For the $\mathrm{Au}$-water interface and an excitation wavelength of $850 \mathrm{~nm}$, the Bragg resonance condition corresponds to a grating period of about $310 \mathrm{~nm}$ (the spatial frequency $\nu=3226 \mathrm{line} / \mathrm{mm})$. If the refractive index in the medium that contacts with gold is larger, the resonance condition is satisfied at smaller values of grating period. In particular, for glycerol, the
Bragg resonance corresponds to a period of $277 \mathrm{~nm}$ $(\nu=3610$ line $/ \mathrm{mm})$. Proceeding from those estimations, the IL method was used to fabricate specimens with the spatial frequency of a periodic nanorelief $\nu=(3370 \pm 5)$ line $/ \mathrm{mm}$ (a period of $296.7 \pm 0.5 \mathrm{~nm}$ ).

A large role in the formation of a chalcogenide lithographic mask in the IL technology is played by the optimization of the exposition process and the photoresist treatment after the exposition. Therefore, in order to obtain a mask with given parameters, it is necessary to choose the optimum thickness of a photoresist, exposure time, etchant selectivity, and photoresist etching time. In the IL technology, the time of the photoresist exposure is slightly exceeded to provide a cycloid profile for grooves in a periodic chalcogenide mask. By varying the time of the selective photoresist etching, the width of elements in the lithographic mask and, so, the width of open intervals between the mask elements, through which the gold layer will be etched further, can be changed.

In Fig. 1, $a$, the AFM image of a grating with a period of $296.7 \pm 0.5 \mathrm{~nm}$ is shown. The grating was formed on a gold layer $50 \mathrm{~nm}$ in thickness with the help of IL and with the use of an $\mathrm{As}_{40} \mathrm{~S}_{60}$ photoresist. The periodic photoresistive mask on this specimen was formed with the ratio between the groove width and the width of the interval between grooves (the width-to-gap ratio for the periodic structure) close to unity. The time of the gold etching through a chalcogenide mask was $40 \mathrm{~s}$. The histogram for groove heights made it possible to determine the average depth of the grating relief, which amounted to $18.5 \pm 2 \mathrm{~nm}$.

In Fig. 1, $b$, the AFM image of a grating with similar parameters (the period and conditions of photoresistive mask formation) is shown. The corresponding time of the gold etching through a similar mask was $25 \mathrm{~s}$. As a result, the average depth of the lattice relief is substantially smaller and amounts to $11.7 \pm 2 \mathrm{~nm}$.

The emergence of a periodic grating on the gold film surface brings about a variation in the shape of an angular dependence of the reflection from the working surface of a sensor chip in a vicinity of the resonance in comparison with the same dependence for a non-structured standard $\mathrm{Au}$ film. In Fig. 2, a, SPR curves (dependences of the reflection coefficient $R$ on the incidence angle $\theta$ ) are shown for a standard $\mathrm{Au}$ chip with a flat surface that contacts with the media (aqueous glycerol solution) with various refrac- 

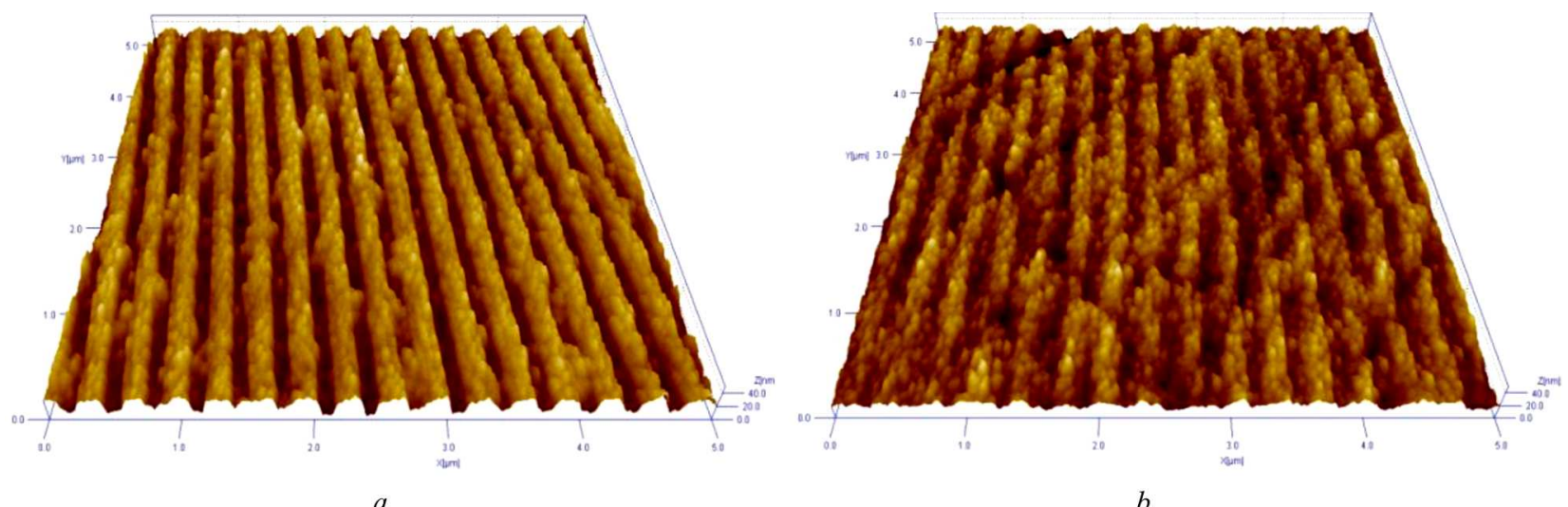

Fig. 1. AFM image of an Au grating with a period of $296.7 \pm \pm 0.5 \mathrm{~nm}$ and an average relief depth of $18.5 \pm 2 \mathrm{~nm}(a)$ and $11.7 \pm 2 \mathrm{~nm}(b)$. The thickness of the initial gold layer amounts to about $50 \mathrm{~nm}$
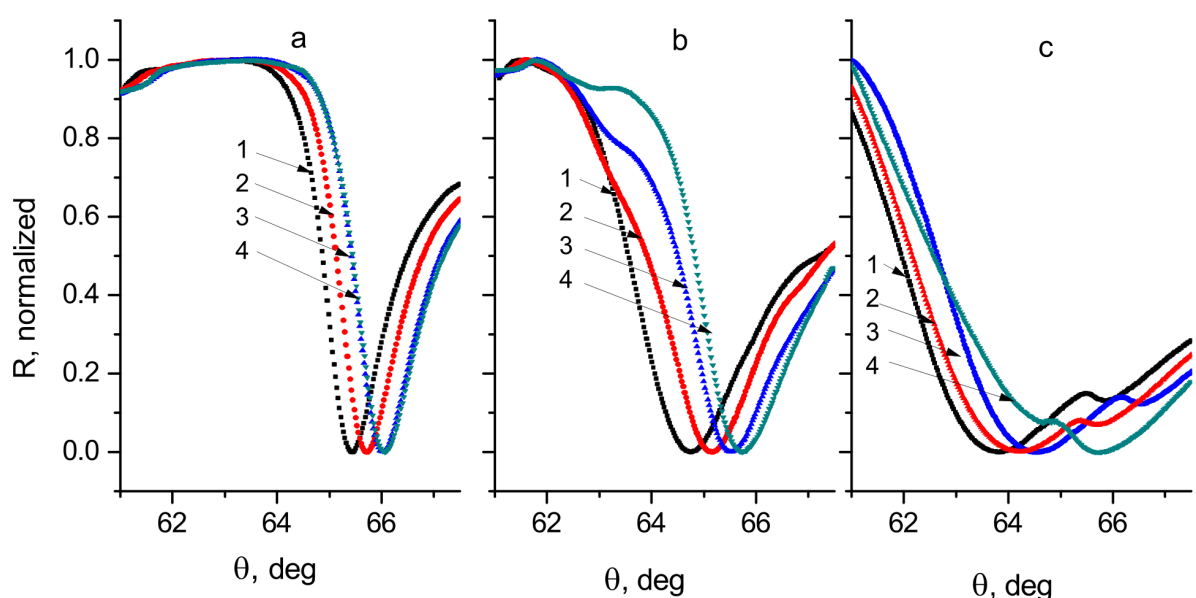

Fig. 2. Dependences of the reflection coefficient $R$ on the incidence angle $\theta$ for a standard Au chip with a flat surface $(a)$ and with Au gratings shown in Fig. 1 with an average relief depth of $11.7 \pm 2 \mathrm{~nm}(b)$ and $18.5 \pm 2 \mathrm{~nm}(c)$

tive index values. Curve 1 corresponds to $n=1.3925$, curve 2 to $n=1.3952$, curve 3 to $n=1.3984$, and curve 4 to $n=1.4023$. One can see that, with the increase of the medium refractive index, the position of the plasmon resonance minimum, $\theta_{\min }$, shifts toward larger angles and increases by $1^{\circ}$, when $n$ grows by about 0.01 . The ratio between the magnitude of the minimum position shift $\Delta \theta_{\min }$ and the corresponding change of the refractive index $\Delta n$ also characterizes the sensitivity of the method with respect to variations of $n$ in the medium near the metal film surface.

Figure 2, $b$ demonstrates similar dependences for a chip with the structured surface, whose relief parameters correspond to Fig. 1, $b$ (grating with shallower grooves). The chip is oriented so that the incidence plane of a probing beam is perpendicular to the grating grooves. One can see that the resonance curve is a little broadened, and the shift of the minimum in the same interval of refractive index variation is slightly larger, $\Delta \theta_{\min }=1.4^{\circ}$, which testifies to the corresponding growth of the structured chip sensitivity in comparison with that of the standard chip in the given variation interval of the medium refractive index.

In Fig. 2, $c$, the SPR curves for a grating with a larger relief depth (corresponding to Fig. 1, a) are shown in the same interval of refractive index variation. In this case, the resonance curves are even more broadened, and two minima are observed. Those measurements agree with the results of theoretical simu- 
lation carried out in work [13], where it was shown that, for a periodic relief $20-40 \mathrm{~nm}$ in depth, the SPR curve has a two-mode structure with two minima in a vicinity of the Bragg resonance. The corresponding shift of the absolute minimum in the SPR curve is even larger in this case, $\Delta \theta_{\min }=1.86^{\circ}$.

The dependences of the SPR resonance location $\theta_{\min }$ on the refractive index of the medium are depicted in Figs. 3 and 4 in more details. Figure 3 (curve 1) illustrates the dependence of $\theta_{\min }$ on $n$ for a standard Au chip with the non-structured surface. One can see that, with the growth of $n$, the value of $\theta_{\min }$ also increases monotonically, and the slope of this dependence (ratio between $\Delta \theta_{\min }$ and $\Delta n$ ) is almost constant within the whole examined interval of the medium refractive index variation. Curve 2 in Fig. 3 corresponds to a chip with the surface structured in the form of a grating with a shallow relief (corresponding to Fig. 1, b). For the structured chip, the dependence of $\theta_{\min }$ on $n$ is nonlinear. In particular, when the Bragg resonance condition is approached, the slope of this dependence substantially decreases in comparison with the result obtained for the standard chip. Then the section with an increased steepness (and, accordingly, with a higher sensitivity) is observed in the interval of refractive index variation from 1.392 to $1.4(\Delta n=0.008$; in Fig. 3, this section lies between two vertical dashed lines). If the refractive index of the medium $n$ grows further, both the standard and structured chips have the same sensitivity. In Fig. 3, the experimental points obtained for both the standard and structured chips in the section of enhanced sensitivity are approximated by straight line segments. The ratio between the slopes of those segments, i.e. the sensitivity ratio between the structured and standard chips, amounts to 1.4.

In Fig. 4, the dependences $\theta_{\min }(n)$ are depicted for a standard Au chip (curve 1) and a structured specimen with a deeper grating relief corresponding to the image in Fig. 1, a (curve 2). As a result of the grating relief depth growth, the non-linear character of the dependence of $\theta_{\min }$ on $n$ becomes substantially stronger. Even the section with a negative slope is observed (from $n=1.38$ to $n=1.39$ ), where $\theta_{\text {min }}$ decreases, as $n$ grows. The section with a higher steepness (sensitivity), which is distinguished in the figure by vertical dashed lines, becomes considerably narrower $(\Delta n=0.0034)$ in comparison with that for the chip with a shallow grating relief, but the steepness

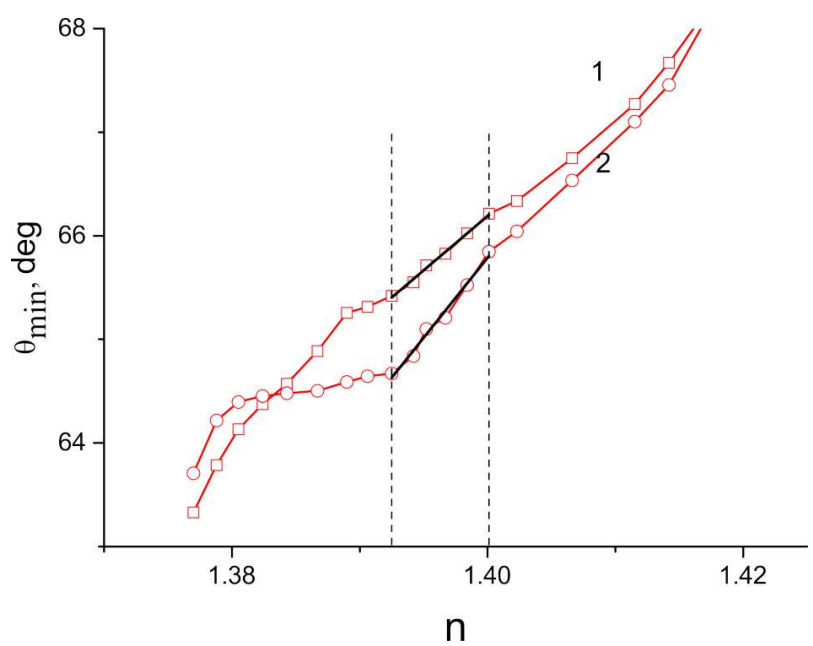

Fig. 3. Dependences of the SPR resonance position $\theta_{\min }$ on the medium refractive index $n$ for the standard Au chip with a flat surface (1) and with an Au grating with a relief depth of $11.7 \pm 2 \mathrm{~nm}$ (2)

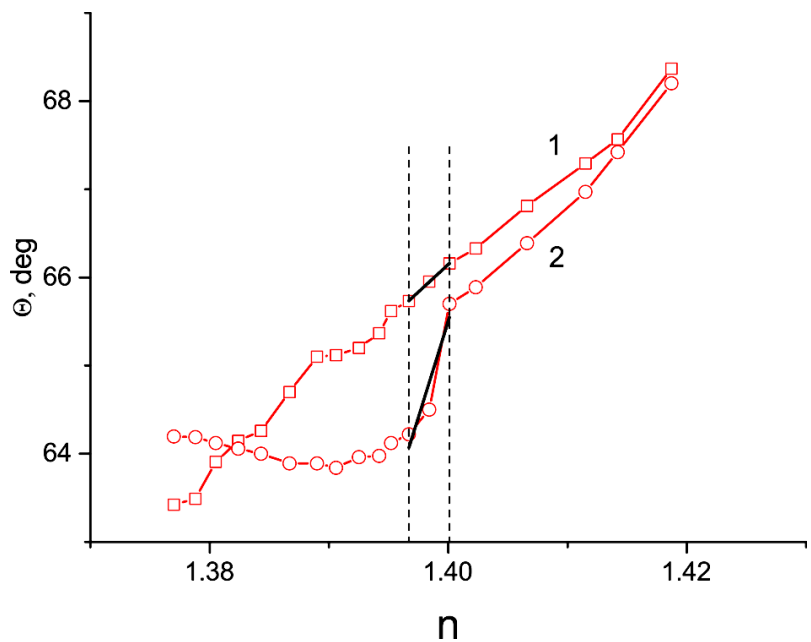

Fig. 4. Dependences $\theta_{\min }(n)$ for the standard Au chips with a flat surface (1) and with an Au grating with an average relief depth of $18.5 \pm 2 \mathrm{~nm}$ (2)

magnitude is considerably larger. The ratio between the slopes of segments that approximate experimental points for the standard and structured chips in the interval of higher sensitivity amounts to 3.3 for this specimen. The corresponding numerical values of sensitivity grow from $110 \mathrm{deg} / \mathrm{RIU}$ for the standard chip to $154 \mathrm{deg} / \mathrm{RIU}$ for the structured chip with the shallow relief, and to $363 \mathrm{deg} / \mathrm{RIU}$ for the chip with the deeper grating relief (here, RIU is the refractive index unit). It should be noted that, in accordance with 
the results of theoretical simulation [13], the maximum factor for the sensitivity enhancement in such sensor controls due to the formation of a grating with a frequency close to that corresponding to the Bragg resonance conditions amounts to $6-6.5$.

Hence, the growth of the sensitivity for sensor chips owing to the nanostructuring of their surface can be observed in a confined interval of medium refractive index variation. This conclusion agrees with the theoretical results of work [13], where the enhancement was predicted in a $\Delta n$-interval narrower than 0.01 . By varying the spatial frequency of the grating relief on the chip surface, it is possible to choose the operational interval with a higher sensitivity for the sensor control, which would correspond to the refractive index of the researched medium.

Biochemical processes that are studied with the help of SPR refractometers are often accompanied by the sedimentation of biomolecule monolayers and very small variations of the refractive index. Therefore, the enhancement of the sensitivity of those sensors even in the narrow intervals of $n$-variation is a challenging task, because even the interval $\Delta n=0.01$ is by 2 to 3 orders of magnitude larger than the sensitivity threshold for SPR refractometers. In particular, the experimental error obtained when determining the angular position of the SPR minimum is about $0.0005^{\circ}$ for a refractometer PLAZMON-71. For a sensitivity of $100 \mathrm{deg} / \mathrm{RIU}$, this value corresponds to the variation of the medium refractive index by $5 \times 10^{-6}$.

\section{Conclusions}

It was shown that the IL technology, in which vacuum chalcogenide photoresists are used, makes it possible to fabricate structured chips with required characteristics (spatial frequency, relief depth, and shape of profile elements) for SPR refractometers.

The results of measurements obtained for the sensor sensitivity in a liquid medium confirm the theoretical prediction about the enhancement of the SPR biosensor sensitivity due to the formation of a grating with the corresponding period and relief depth on the operational chip surface. It is found that the coefficient of sensitivity growth and the interval of refractive index variation, in which this growth is observed, depend on the grating relief depth. As the relief depth increases, the width of the working interval for the medium refractive index $n$ decreases, and the coefficient of sensitivity enhancement increases.
The work was sponsored in the framework of the SCOPES program of the Swiss National Foundation of Scientific Researches (grant IZ73Z0_152661).

1. C. Nylander, B. Liedberg, T. Lind. Gas detection by means of surface plasmon resonance. Sens. Actuat. 3, 79 (1982).

2. B. Moslehi, M.W. Foster, P. Harvey. Optical magnetic and electric field sensors based on surface plasmon polariton resonant coupling. Electron. Lett. 27, 951 (1991).

3. A. Schilling, O. Yavaş, J. Bischof, J. Boneberg, P. Leiderer. Absolute pressure measurements on a nanosecond time scale using surface plasmons. Appl. Phys. Lett. 69, 4159 (1996).

4. H.-M. Schmitt, A. Brecht, J. Piehler, G. Gauglitz. An integrated system for optical biomolecular interaction analysis. Biosens. Bioelectron. 12, 809 (1997).

5. L. Huang, G. Reekmans, D. Saerens, J.-M. Friedt, F. Frederix, L. Francis, S. Muyldermans, A. Campitelli, C. Van Hoof. Prostate-specific antigen immunosensing based on mixed self-assembled monolayers, camel antibodies and colloidal gold enhanced sandwich assays. Biosens. Bioelectron. 21, 483 (2005).

6. E. Mauriz, A. Calle, J.J. Manclús, A. Montoya, L.M. Lechuga. Multi-analyte SPR immunoassay for enviromental biosensing of pesticides. Analyt. Bioanalyt. Chem. 387, 1449 (2007).

7. P.D. Patel. Overview of affinity biosensors in food analysis. J. AOAC Int. 89, 805 (2006).

8. E. Kretschmann, H. Raether. Radiative decay of nonradiative surface plasmons excited by light. Z. Naturforsch. 23A, 2135 (1968).

9. P. Englebienne, A. Van Hoonacker, M. Verhas. Surface plasmon resonance: principles, methods and applications in biomedical sciences. Spectroscopy 17, 255 (2003).

10. R.S. Moirangthem, Y.-C. Chang, P.-K. Wei. Ellipsometry study on gold-nanoparticle-coated gold thin film for biosensing application. Biomed. Opt. Express 2, 2569 (2011).

11. K.M. Byun, S.J. Yoon, D. Kim, S.J. Kim. Experimental study of sensitivity enhancement in surface plasmon resonance biosensors by use of periodic metallic nanowires. Opt. Lett. 32, 1902 (2007).

12. W.P. Hu, S.-J. Chen, K.-T. Huang, J.H. Hsu, W.Y. Chen, G.L. Chang, K.-A. Lai. A novel ultrahigh-resolution surface plasmon resonance biosensor with an $\mathrm{Au}$ nanoclusterembedded dielectric film. Biosens. Bioelectron. 19, 1465 (2004).

13. C.J. Alleyne, A.G. Kirk, R.C. McPhedran, N-A.P. Nicorovici, D. Maystre. Enhanced SPR sensitivity using periodic metallic structures. Opt. Express 15, 8163 (2007).

14. A. Cattoni, E. Cambril, D. Decanini, G. Faini, A.M. Haghiri-Gosnet. Soft UV-NIL at $20 \mathrm{~nm}$ scale using flexible bi-layers tamp casted on HSQ master mold. Microelectr. Eng. 87, 1015 (2010).

ISSN 2071-0194. Ukr. J. Phys. 2017. Vol. 62, No. 5 
15. Y. Fu, N. Kok, A. Bryan, W. Zhou. Self-organized formation of a Blazed-grating-like structure on $\mathrm{Si}(100)$ induced by focused ion-beam scanning. Opt. Express 12, 1803 (2004).

16. X.Y. Zhang, A.V. Whitney, J. Zhao, E.M. Hicks, R.P. Van Duyne. Advances in contemporary nanosphere lithographic techniques. J. Nanosci. Nanotechnol. 6, 1920 (2006).

17. S.Y. Chuang, H.L. Chen, S.S. Kuo, Y.H. Lai, C.C. Lee. Using direct nanoimprinting to study extraordinary transmission in textured metal films. Opt. Express 16, 2415 (2008).

18. F. Brizuela, Y. Wang, C.A. Brewer, F. Pedaci, W. Chao, E.H. Anderson, Y. Liu, K.A. Goldberg, P. Naulleau, P. Wachulak, M.C. Marconi, D.T. Attwood, J.J. Rocca, C.S. Menoni. Microscopy of extreme ultraviolet lithography masks with $13.2 \mathrm{~nm}$ tabletop laser illumination. Opt. Lett. 34, 271 (2009).

19. A. Arriola, A. Rodriguez, N. Perez, T. Tavera, M.J. Withford, A. Fuerbach, S.M. Olaizola. Fabrication of high quality sub-micron $\mathrm{Au}$ gratings over large areas with pulsed laser interference lithography for SPR sensors. Opt. Mater. Express 2, 1571 (2012).

20. M. Vala, J. Homola. Flexible method based on fourbeam interference lithography for fabrication of large areas of perfectly periodic plasmonic arrays. Opt. Express 22, 18778 (2014).

21. I.Z. Indutnyi, V.I. Myn'ko, P.E. Shepeliavyi, M.V. Sopins'kyi, V.M. Tkach, V.A. Dan'ko. Photonic nanostructure formation using interference lithography and deposition at a gtrazingn incidence angle in vacuum. Optoelektr. Poluprovodn. Tekhn. 46,4 9 (2011) (in Russian).

22. V. Dan'ko, I. Indutnyi, M. Min'ko, P. Shepelyavyi. Instrumentation and Data Processing. Interference photolithography with the use of resists on the basis of chalcogenide glassy semiconductors. Optoelectron. Instrument. Proc. 46, 483 (2010).
23. V.A. Dan'ko, G.V. Dorozinsky, I.Z. Indutnyi, V.I. Myn'ko, Yu.V. Ushenin, P.E. Shepeliavyi, M.V. Lukaniuk, A.A. Korchovyi, R.V. Khrystosenko. Nanopatterning Au chips for SPR refractometer by using interference lithography and chalcogenide photoresist. Semiconductor Physics, Quantum Electronics \& Optoelectronics 18, 438 (2015).

Received 03.05.16.

Translated from Ukrainian by O.I. Voitenko

I.З. Індутний, Ю.В. Ушенін,

В.І. Минъко, П.Є. Шепелявий, М.В. Луканюк,

A.А. Корчовий, Р.В. Христосенко

НАНОСТРУКТУРОВАНІ Аи ЧІПИ

З ПІДВИЩЕНОЮ ЧУТЛИВІСТЮ ДЛЯ СЕНСОРІВ

НА ОСНОВІ ПОВЕРХНЕВОГО

ПЛАЗМОННОГО РЕЗОНАНСУ

$\mathrm{P}$ е $з$ ю м е

В роботі проведені дослідження підвищення чутливості поверхневого плазмонного резонансу рефрактометра за рахунок формування періодичного рельєфу у вигляді гратки з субмікронним періодом на поверхні $\mathrm{Au}$ чіпа. Періодичний рельєф різної глибини 3 просторовою частотою $\nu=(3370 \pm 5)$ лін./мм було сформовано на поверхні плівки $\mathrm{Au}$ за допомогою інтерференційної літографії з використанням вакуумних халькогенідних фоторезистів. Встановлено, що кратність підвищення чутливості рефрактометра та величина інтервалу зміни показника заломлення $\Delta n$ середовища, в якому спостерігається це підвищення, залежить від глибини рельєфу гратки. При збільшенні глибини рельєфу ширина робочого інтервалу $\Delta n$ зменшується, а чутливість збільшується від 110 град./RIU для стандартного чіпа, до 154 град./RIU та 363 град./RIU для структурованих чіпів 3 глибиною рельєфу, що дорівнює $11,7 \pm 2$ нм та 18,5 \pm 2 нм відповідно. 